\title{
MAPEAMENTO DIGITAL DE SOLOS: A PREDIÇÃO DA OCORRÊNCIA DO NEOSSOLO QUARTZARÊNICO NOS MUNICÍPIOS DE CANUDOS E JEREMOABO - BAHIA
}

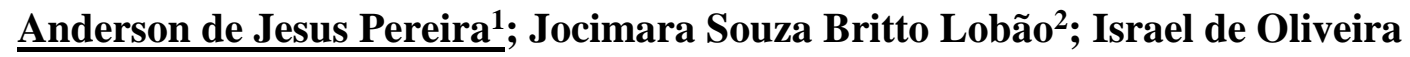 \\ Junior $^{3}$ \\ 1. Bolsista PROBIC/UEFS, Graduando em Agronomia, Universidade Estadual de Feira de Santana (UEFS), e-mail: \\ dinho_sa@hotmail.com \\ 2. Orientadora, Departamento de Ciências Humanas e Filosofia (DCHF), UEFS, e-mail: juci.lobão@gmail.com \\ 3. Participante do Grupo de Pesquisa CNPq Natureza, Sociedade e Ordenamento Territorial, DCHF, UEFS, e-mail: \\ iojjunior@gmail.com
}

PALAVRAS-CHAVE: modelagem; paisagem; fragilidade ambiental.

\section{INTRODUÇÃO}

Os solos constituem elementos indispensáveis para a ocorrência da vida na Terra e sua qualidade determina, de forma significativa, a natureza dos ecossistemas das plantas e a capacidade da Terra em sustentar a vida animal e dos seres humanos. À medida que alteramos as características superficiais da terra, menos contato direto temos com o solo, e perdemos de vista o quanto dependemos dele para nossa sobrevivência e desenvolvimento (BRADY\& WEIL, 2013).

O mapeamento preditivo de ocorrência de Neossolo quartzarênico constitui um caminho para a identificação das características das paisagens de alta vulnerabilidade ambiental à desertificação no estado da Bahia (AB'SABER, 1977; LOBÃO \& SILVA, 2013; OLIVEIRA JUNIOR, 2014). A desertificação ocorre em áreas de clima árido, semiárido e subúmido seco, a partir da destruição do potencial produtivo do solo (UNCCD, 1997). Quando os solos se tornam inférteis é porque a desertificação já se materializou no ambiente, como uma consequência das práticas insustentáveis. $\mathrm{O}$ Neossolo quartzarênico é um solo susceptível aos processos de erosão acelerada, a qual constitui um dos piores processos da degradação do solo no mundo, além de ser o principal processo associado ao abandono de terra e à desertificação (KOMAS et al., 2010).

Todo o uso localizado em terras secas que não consideram a fragilidade dos ecossistemas poderá provocar a desertificação, pois eles apresentam um equilíbrio delicado, em especial, durante a época de estiagem pluviométrica (HARE et al., 1992). Com isso, por meio deste estudo, objetivou-se elaborar o mapeamento preditivo de ocorrência de Neossolo quartzarênico, a partir da aplicação de técnicas de geoprocessamento, para fundamentar as discussões sobre a susceptibilidade à desertificação no contexto dos municípios baianos de Canudos e Jeremoabo.

\section{MATERIAIS E MÉTODOS}

A área de estudo abrange os municípios de Canudos e Jeremoabo, localizados no norte do estado da Bahia. Eles integram a área suscetível à desertificação (ASD) do Brasil e neles há indícios de ambiente de vulnerabilidade à desertificação, como apontaram alguns estudos (AB'SABER, 1977; OLIVEIRA JUNIOR, 2014; LOBÃO \& SILVA, 2013).

A execução do estudo baseou-se, inicialmente, em uma revisão bibliográfica, para auxiliar na melhor definição do problema, contendo discussões sobre a modelagem ambiental, logica fuzzy, pedologia, neossolo quartzarênico e temas afins na literatura. Junto a essa etapa, realizou-se a revisão cartográfica, para identificação de produtos préexistentes interessantes ao mapeamento preditivo de ocorrência de Neossolo quartzarênico. Com isso, construiu-se um banco de dados em formato de sistema de informação geográfica (SIG), com arquivos relacionados ao clima, relevo, litologia, 
solo, vegetação, uso da terra, de fontes secundárias, como aqueles disponibilizados pelo SIG-BA (2003) e Oliveira Junior (2014). Elaborou-se mapas de variáveis do relevo, como declividade, perfil de curvatura, plano de curvatura e índice topográfico de umidade. Os dados foram extraídos do modelo digital de terreno (MDT), com resolução de 30m (NASA, 2013), a partir da aplicação de técnicas de geoprocessamento. Os dados foram integrados no SIG da pesquisa, para análise da paisagem dos municípios e configuração de cenários ambientais.

A definição dos planos de informações e métodos empregados para a modelagem ambiental adaptou-se de Nolasco-Carvalho $(2009,2015)$ e Nolasco et al. (2009). Empregou-se a lógica fuzzy para a integração dos planos de informações no processo de mapeamento preditivo de Neossolo quartzarênico. Cada classe dos planos de informações utilizados para a modelagem compreendeu valores correspondentes aos níveis de pertencimento fuzzy num intervalo entre zero e um, sem restrições dos valores intermediários. Sabe-se que quanto mais próximo do valor um, maior a pertinência ao fenômeno que se quer evidenciar, por isso os limites das classes foram determinados em função da importância da classe de susceptibilidade. No processo de análise ambiental e verificação dos produtos elaborados pelas técnicas de geoprocessamento, realizou-se estudos de campo, nos quais preencheu-se planilhas com informações ambientais e obteve-se as coordenadas geográficas para integração dos dados ao SIG da pesquisa.

\section{RESULTADOS E DISCUSSÃO}

No processo de elaboração do mapa de Neossolo quartzarênico, realizou-se, em ambiente SIG, integrações de planos de informações, no intuito de identificar quais eram importantes para estabelecer a distribuição do referido solo, atrelados com os dados levantados em campo. No total, elaborou-se nove modelos, com a aplicação dos diferentes operadores fuzzy, incluindo, ou não, os mapas de declividade, plano de curvatura, perfil de curvatura, índice topográfico de umidade, litotipo, vegetação e altitude. Foram realizados testes com os operadores and, somma algébrica e gamma, e verificou-se que o gamma, com expoente 7 , constituiu no mais eficiente para o mapeamento na área de estudo, pois a modelagem indicou uma maior proximidade ao real.

Em razão dos resultados do modelo, percebeu-se a importância dos dados referentes à declividade, índice topográfico de umidade, litotipo, perfil de curvatura e plano de curvatura para estabelecer a ocorrência do Neossolo quartzarênico nos municípios de Canudos e Jeremoabo. Os critérios estabelecidos para a integração no intuito de gerar o mapa de neossolo quartzarênico encontram-se sistematizados no quadro 1.

Após o processamento dos dados, produziu-se o mapa de predição da ocorrência de Neossolo quartzarênico em uma escala de 1/100000 (Figura 1), o que denota um detalhamento pedológico para a área de estudo, e identificou-se que a referida classe de solo (Figura 1) distribui-se em 67,55\% da área de estudo (Figura 1), valor estatisticamente semelhante ao total encontrado no mapa convencional 67,60\% (SIGBA, 2003). No entanto, há distinções perceptíveis, como no detalhamento dos locais de ocorrência, mostrando que o referido solo se encontra concentrado no centro da área de estudo e dispersam-se em diferentes pontos (Figura 1), com ocorrência no oeste, ao contrário do que é mostrado no mapa convencional. Isso deveu-se, sobretudo, às escalas dos mapas e ao processamento dos dados, com a demonstração da importância do geoprocessamento para a produção de informações ambientais detalhadas e com rigor científico. 
Quadro 1 - Mapas e graus de pertencimento - mapeamento preditivo de Neossolo quartzarênico

\begin{tabular}{|c|c|c|c|c|c|}
\hline Dado & Classe & Nível fuzzy & Dado & Classe & Nível fuzzy \\
\hline \multirow[t]{15}{*}{ Litotipo } & Arenito & 1 & \multirow[t]{22}{*}{ Vegetação } & \multirow{2}{*}{$\begin{array}{l}\text { Caatinga arbórea- } \\
\text { arbustiva }\end{array}$} & \multirow[t]{2}{*}{0,9} \\
\hline & Micaxisto & 0 & & & \\
\hline & Calcário & 0 & & \multirow{3}{*}{$\begin{array}{l}\text { Caatinga arbórea- } \\
\text { arbustiva } \\
\text { antropizada }\end{array}$} & \multirow[t]{3}{*}{0,9} \\
\hline & Granito & 0 & & & \\
\hline & Filito & 0 & & & \\
\hline & Metagranito & 0 & & Caatinga parque & 0,3 \\
\hline & $\begin{array}{l}\text { Sedimento } \\
\text { aluvionar }\end{array}$ & 1 & & $\begin{array}{l}\text { Caatinga parque } \\
\text { antropizada }\end{array}$ & 0,3 \\
\hline & Anfibolito & 0 & & Campo rupestre & 0,1 \\
\hline & Areia & 1 & & Cidade & 0 \\
\hline & $\begin{array}{l}\text { Arcoseo } \\
\text { lítico }\end{array}$ & 0 & & Lago & 0 \\
\hline & Gnaisse & 0 & & \multirow{3}{*}{$\begin{array}{ll}\text { Lavoura } & \text { e } \\
\text { pastagem } & \\
\text { alternadas } & \end{array}$} & \multirow[t]{3}{*}{0,4} \\
\hline & Calcarenito & 0,5 & & & \\
\hline & Metabásica & 0 & & & \\
\hline & Calcilulito & 0 & & Lavoura irrigada & 0,3 \\
\hline & Monsogranito & 0 & & Pastagem & 0,5 \\
\hline \multirow[t]{5}{*}{ Declividade } & Plano & 1 & & Solo exposto & 0,6 \\
\hline & $\begin{array}{l}\text { Suave- } \\
\text { ondulado }\end{array}$ & 0,7 & & \multirow[t]{2}{*}{$\begin{array}{l}\text { Superfície erosiva } \\
\text { flúvio-pluvial }\end{array}$} & \multirow[t]{2}{*}{0,2} \\
\hline & Ondulado & 0 & & & \\
\hline & $\begin{array}{l}\text { Forte- } \\
\text { ondulado }\end{array}$ & 0 & & \multirow{3}{*}{$\begin{array}{l}\text { Vegetação com } \\
\text { influencia } \\
\text { lacustre e fluvia }\end{array}$} & \multirow[t]{3}{*}{0,1} \\
\hline & Montanhoso & 0 & & & \\
\hline \multirow{3}{*}{$\begin{array}{l}\text { Perfil de } \\
\text { curvatura }\end{array}$} & Côncavo & 0,6 & & & \\
\hline & Convexo & 0,2 & & Vila & 0 \\
\hline & Retilíneo & 0,5 & \multirow{5}{*}{$\begin{array}{l}\text { Índice } \\
\text { topográfico de } \\
\text { umidade }\end{array}$} & Muito-baixo & 0,3 \\
\hline \multirow{4}{*}{$\begin{array}{l}\text { Plano de } \\
\text { curvatura }\end{array}$} & Convergente & 0,2 & & Baixo & 0,6 \\
\hline & Divergente & 0,6 & & Médio & 0,6 \\
\hline & Retilíneo & 0,4 & & Alto & 1 \\
\hline & & & & Muito-alto & 1 \\
\hline
\end{tabular}

Fonte: Anderson de Jesus Pereira, 2017

Figura 1 - Canudos e Jeremoabo: predição de ocorrência do Neossolo quartzarênico

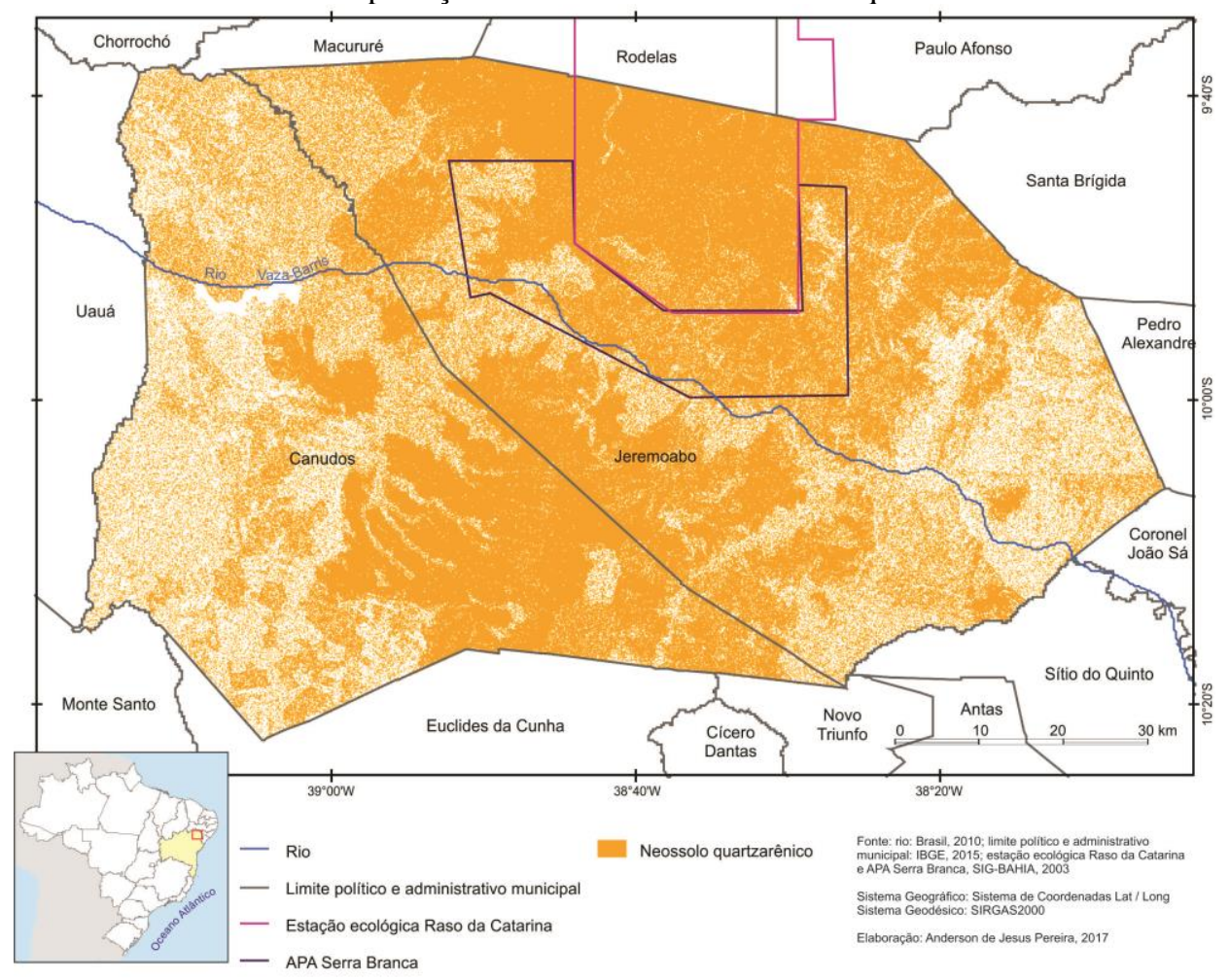




\section{CONSIDERAÇÕES FINAIS}

Nos estudos utilizados por meio da revisão bibliográfica e dos levantamentos de dados em campo, identificou-se a fragilidade ambiental do neossolo quartzarênico. Por isso, elaborou-se o mapa de predição de ocorrência Neossolo quartzarênico, em função de detalhar a ocorrência deles nos municípios de Canudos e Jeremoabo, bem como de realizar teste para identificar os procedimentos metodológicos de elaboração do mapa digital de solo.

Existem planos de informações que são importantes na identificação dos solos, como os relacionados as variáveis do relevo (declividade, perfil de curvatura, plano de curvatura, índice topográfico de umidade), litologia e uso e cobertura da terra. A integração deles por meio da lógica fuzzy, operador gamma possibilitou determinar a ocorrência do Neossolo quartzarênico, o que se aproximou fortemente da realidade ambiental da área de estudo. O referido solo é encontrado sobre os tabuleiros, formados por arenitos, bem como se dispersa em outras paisagens constituídas por relevo plano, onde crescem, sobretudo, a caatinga arbórea e arbustiva.

Essas áreas necessitam de atenção no uso da terra, em função de, neste estudo, identificar a fragilidade ambiental. O referido solo é muito friável e as a utilização sucessiva nas práticas agropecuárias podem intensificar os processos erosivos e aceralos, a ponto de os tornarem degradados. Em alguns pontos já foram identificados níveis de deterioração ambiental, o que preocupa. A ampliação da pressão ambiental em um ambiente de fragilidade ambiental, em razão da interação clima-solo-vegetação, pode desencadear a desertificação.

\section{REFERÊNCIAS}

AB'SABER, A. 1977. N. Problemática da desertificação e da savanização no Brasil intertropical. Geomorfologia. São Paulo, 53: 1-19.

BRADY, N. C.; WEIL, R. R. 2013. Elementos da natureza e propriedades dos olhos. 3. ed. Porto Alegre, Bookman.

HARE, F. K. et al. 1992. Desertificação: causas e consequências. Lisboa, Calouste Gulbenkian.

KOSMAS, C.; YASSOGLOU, N.; KOUNALAKI, A.; KAIRIS, O. 2010. Abandono da Terra. Land Care in Desertification Affected Areas. 4: 1-13.

LOBÃO, J. S. B.; SILVA, B. C. N. 2013. Análise socioambiental na região semiárida da Bahia: geoprocessamento como subsídio ao ordenamento territorial. Feira de Santana, UEFS Editora.

NOLASCO-CARVALHO, C. C.; FRANCA-ROFHA. W. S.; UCHOA, J. M. 2009. Mapa digital de solos: uma proposta metodológica usando inferência fuzzy. Revista Brasileira de Engenharia Agrícola e Ambiental, Campina Grande, 13 (1): 46-55.

NOLASCO-CARVALHO, C. C. Inferência fuzzy para predição de classes de solo em áreas de assentamentos na microrregião da Mata Alagoana. Universidade Federal Rural do Rio de Janeiro, Rio de Janeiro, Tese.

OLIVEIRA JUNIOR, I. 2014. O processo de desertificação: a vulnerabilidade e a degradação ambiental no polo regional de Jeremoabo - Bahia. Universidade Federal da Bahia, Salvador, Dissertação.

SISTEMA DE INFORMAÇÃO GEOREFERENCIADAS - SIG-BAHIA 2003. Sistema de Informações sobre Recursos Hídricos - SIRH. Salvador, Superintendência de Recursos Hídricos.

UNCCD. 1997. Convenção das Nações Unidas de combate à desertificação nos países afetados por seca grave elou desertificação, particularmente na África. Brasília, DF, Ministério do Meio Ambiente. 